\title{
Pharmacokinetics and Tissue Distribution of Spinosin after Intravenous Administration in Rats
}

\author{
Yu-Juan LI, ${ }^{a}$ Yue-Han DAI, ${ }^{a}$ Ye-Ling YU, ${ }^{b}$ Yan LI, ${ }^{a}$ and Yu-Lin DenG ${ }^{*}, a$ \\ ${ }^{a}$ School of Life Science and Technology, Beijing Institute of Technology, No. 5 South Zhongguancun Street, \\ Haidian District, Beijing 100081, P. R. China and 'bshool of Pharmacy, Shenyang Pharmaceutical \\ University, Wenhua Road 103, Shenhe District, Shenyang 110016, Liaoning Province, P. R. China
}

(Received January 23, 2007; Accepted April 10, 2007)

\begin{abstract}
Spinosin is the major effective single constituent in the traditional Chinese herb Semen Ziziphi Spinosae, which is used for sedation and hypnosis. For the further use of spinosin in treating insomnia, the pharmacokinetics and tissue distribution of spinosin after intravenous administration to rats was investigated. An HPLC method with an ODS column $(250 \mathrm{~mm} \times 4.6 \mathrm{~mm}, i . d$.$) and a mobile phase of acetonitrile-water-acetic acid (23: 77: 1)$ was used for the determination of spinosin in the plasma and tissues of rats. Vanillin was used as an internal standard, and spinosin was detected at $334 \mathrm{~nm}$. The calibration curve of spinosin in plasma showed good linearity over the concentration range of $1-$ $300 \mu \mathrm{g} / \mathrm{ml}$, and the quantitation of limit of plasma was $1 \mu \mathrm{g} / \mathrm{ml}$. The linear range of concentrations of spinosin in the heart, spleen, stomach, lung, testis, brain, and intestine was $0.1-40 \mu \mathrm{g} / \mathrm{ml}$ and the quantitation limit was $0.1 \mu \mathrm{g} / \mathrm{ml}$. The linear range of concentrations of spinosin in the liver and kidney was $1-150 \mu \mathrm{g} / \mathrm{ml}$, and the quantitation limit was $1 \mu \mathrm{g} /$ $\mathrm{ml}$. The correlation coefficients of all calibration curves were between 0.9939 and 0.9980 . The intra and interrun precision for all samples was less than $\leqslant 11.0 \%$. The time-concentration curve of spinosin after the intravenous administration of a single dose of $20 \mathrm{mg} / \mathrm{kg}$ to rats corresponded to the two-compartment model. The main pharmacokinetic parameters $T_{0.5 \alpha}, T_{0.5 \beta}, C L \mathrm{~s}, \mathrm{AUC}_{0-\mathrm{T}}$, and $V_{\mathrm{c}}$ were $6.66 \mathrm{~min}, 51.5 \mathrm{~min}, 1.42 \mathrm{l} \cdot \mathrm{min}^{-1}, 2.83 \mathrm{mg} \cdot \mathrm{min} \cdot \mathrm{ml}^{-1}$, and $14.0 \mathrm{l} \cdot$ $\mathrm{kg}^{-1}$, respectively. At $20 \mathrm{~min}$, a concentration peak occurred in liver and brain tissues. The highest level of spinosin occurred in the liver, followed by the spleen and kidney. The lowest level of spinosin appeared in the testis, followed by the brain. Spinosin was not detected in smooth and skeletal muscle. After intravenous administration, the drug was distributed extensively and transferred quickly in rats in vivo.
\end{abstract}

Key words_— - spinosin; pharmacokinetics; tissue distribution

\section{INTRODUCTION}

Traditional Chinese medicine (TCM) is based on natural therapeutic agents used under the guidance of the theory of TCM theory and has played an indispensable role in the prevention and treatment of disease in China. Suanzaoren (Semen Ziziphi Spinosae) is one famous TCM herb for treating insomnia. ${ }^{1,2)}$ It has been officially listed in the Chinese Pharmacopoeia (2005).2) Suanzaoren contains a series of saponins and flavones. Spinosin (Fig. 1 (a), one flavone-C-glycoside) is one of the major active components in Suanzaoren. It has been widely reported that it plays an important role in sedation and hypnosis. ${ }^{3-6)}$ Our previous research also confirmed that spinosin was one therapeutic component in the TCM preparation Suanzaoren decoction (containing five Chinese herbs with sedation and hypnosis

\footnotetext{
*e-mail: lylyj2003@yahoo.com
}

effects), and it showed perfect correlation with pharmacologic activities in inhibiting spontaneous motion and extending the sleeping duration of mice induced by pentobarbital sodium (super threshold dose). ${ }^{7,8)}$ Spinosin almost showed no adverse effects in animal toxicity experiments. ${ }^{7)}$ It has been selected as a marker compound for quality control in Suanzaoren or other TCM preparations containing spinosin. ${ }^{9-11)}$ However, in vitro study on effective constituents alone is not sufficient for promoting the development

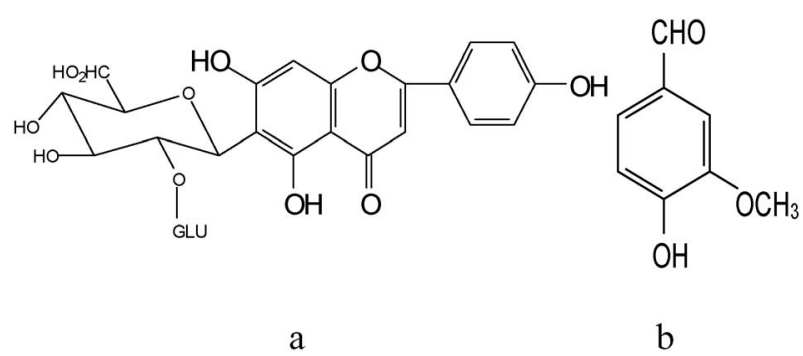

Fig. 1. Chemical Structure of Spinosin (a) and Vanillin (b) 
and modernization of TCM. In vivo study, such as pharmacokinetic studies of active ingredients in Chinese herbs, will have considerable impact on illustrating their mechanism of action and supplying research information for clinical use. The reversephase HPLC method for the determination of spinosin in the plasma of rats after the oral administration of Suanzaoren decoction was developed in our previous research. ${ }^{12,13)}$ It has also been found that spinosin as a single agent was poorly absorbed by rats after oral administration. ${ }^{7)}$ The pharmacokinetic behavior and tissue distribution of spinosin as a single compound after intravenous administration in rats has not been reported elsewhere. To support preclinical pharmacokinetic studies and make better use of this natural compound and TCM preparations containing spinosin, we studied the pharmacokinetics and tissue distribution of spinosin for the first time.

\section{MATERIALS AND METHODS}

\section{Chemicals and Materials Spinosin was supplied} by Shenyang Pharmaceutical University (98.8\% purity); vanillin (Fig. 1 (b)) used as an internal standard (IS) was supplied by Tianxin Chemistry Development Center (Tianjin, China). Methanol and acetonitrile were of chromatographic grade, and glacial acetic acid was of analytical grade from Beijing Yili Chemical Product Co. (Beijing, China). DMSO and heparin were purchased from Solon Industries (Solon, OH, USA) and Aoboxing Bio-technology Co. (Beijing, China), respectively. Healthy Wistar rats (male, $180 \pm 20 \mathrm{~g}$; certificate number 0068704) were supplied by the Experimental Animal Institute of the Medical Science Academy of China.

\section{Chromatographic Conditions A Hypersil $\mathrm{C}_{18}$} $(5 \mu \mathrm{m}, 250 \times 4.6 \mathrm{~mm}$, i.d.) analytical column from Elite Co. (Dalian, China) was used. As the mobile phase, a binary mixture of acetonitrile-water (23 : $77, \mathrm{v} / \mathrm{v})$ containing $1 \%$ glacial acetic acid was delivered via a $\mathrm{P}-230$ pump (Elite Co.) in isocratic mode at a flow rate of $0.8 \mathrm{ml} / \mathrm{min}$. The DAD-230 (Elite Co.) detector was set at $334 \mathrm{~nm}$ and all measurements were performed at room temperature. An EC-2000 workstation was used for data acquisition.

Animal Treatment Each rat $(n=5)$ was administered a single intravenous dose of $20 \mathrm{mg} / \mathrm{kg}$ of spinosin solution (spinosin was first dissolved in DMSO and then diluted to the final concentration with $0.9 \%$ saline solution, the amount of DMSO was less than $0.5 \%$ of the total volume). Blood samples $(0.5 \mathrm{ml})$ were collected after $0,2,5,10,15,30,45$, 60,120 , and $240 \mathrm{~min}$ and then transferred into heparinized tubes. All the samples were centrifuged for $10 \mathrm{~min}$ at $3000 \mathrm{~g}$ and stored at $-70^{\circ} \mathrm{C}$ before use.

After blood collection, major tissue samples (brain, heart, liver, spleen, lung, kidney, stomach, intestine, smooth muscle, skeletal muscle, testis) at 5, 20 , and $60 \mathrm{~min}$ were rapidly collected and placed in normal saline solution to remove blood, then blotted on filter paper. All the tissue samples were weighed and homogenized in methanol (two-fold tissue weight) at $0^{\circ} \mathrm{C}$ using an FJ-2000 homogenizer (Biaoben Model Factory, Shanghai, China). Tissue homogenates were centrifuged for $15 \mathrm{~min}$ at $3500 \mathrm{~g}$ and the supernatants were stored at $-70{ }^{\circ} \mathrm{C}$ until use.

Extraction Procedure To $300 \mu$ l plasma or 400 $\mu \mathrm{l}$ of tissue homogenate, $100 \mu \mathrm{l}$ of IS solution $(0.025$ $\mathrm{mg} / \mathrm{ml}$ ) and 600 or $800 \mu \mathrm{l}$ acetonitrile (for plasma and tissue samples, respectively) were added. Each tube was mixed thoroughly by vortexing for $90 \mathrm{~s}$. After centrifugation for $15 \mathrm{~min}$ at $3500 \mathrm{~g}$, the supernatant was transferred into clean labeled test tubes and evaporated to dryness at room temperature under a stream of nitrogen. The residuals were reconstituted in $100 \mu \mathrm{l}$ of the mobile phase with vortexing for $90 \mathrm{~s}$ and the centrifugation procedure was repeated. Fifteen microliters of aliquot was injected onto the chromatographic column.

\section{RESULTS AND DISCUSSION}

Specificity Under the RP-HPLC conditions used, spinosin and IS were eluted at 5.6 and $9.7 \mathrm{~min}$, respectively. Typical chromatograms of blank plasma, blank plasma spiked with spinosin and IS, and rat plasma sample after intravenous administration of spinosin a shown in Fig. 2. Good separation of IS and spinosin was achieved under the chromatographic conditions. The resolution between spinosin and IS was greater than 1.5. Simple protein precipitation with acetonitrile was sufficient to isolate the analytes from the biological matrix without any interfering endogenous peaks.

Calibration and Validation Different amounts of spinosin and $100 \mu \mathrm{l}$ of IS were added to $300 \mu \mathrm{l}$ of blank plasma or $400 \mu \mathrm{l}$ of tissue homogenate to obtain the spiked samples with the final concentration ranges shown in Table 1 . The samples were then treated with the above extraction procedures and ana- 

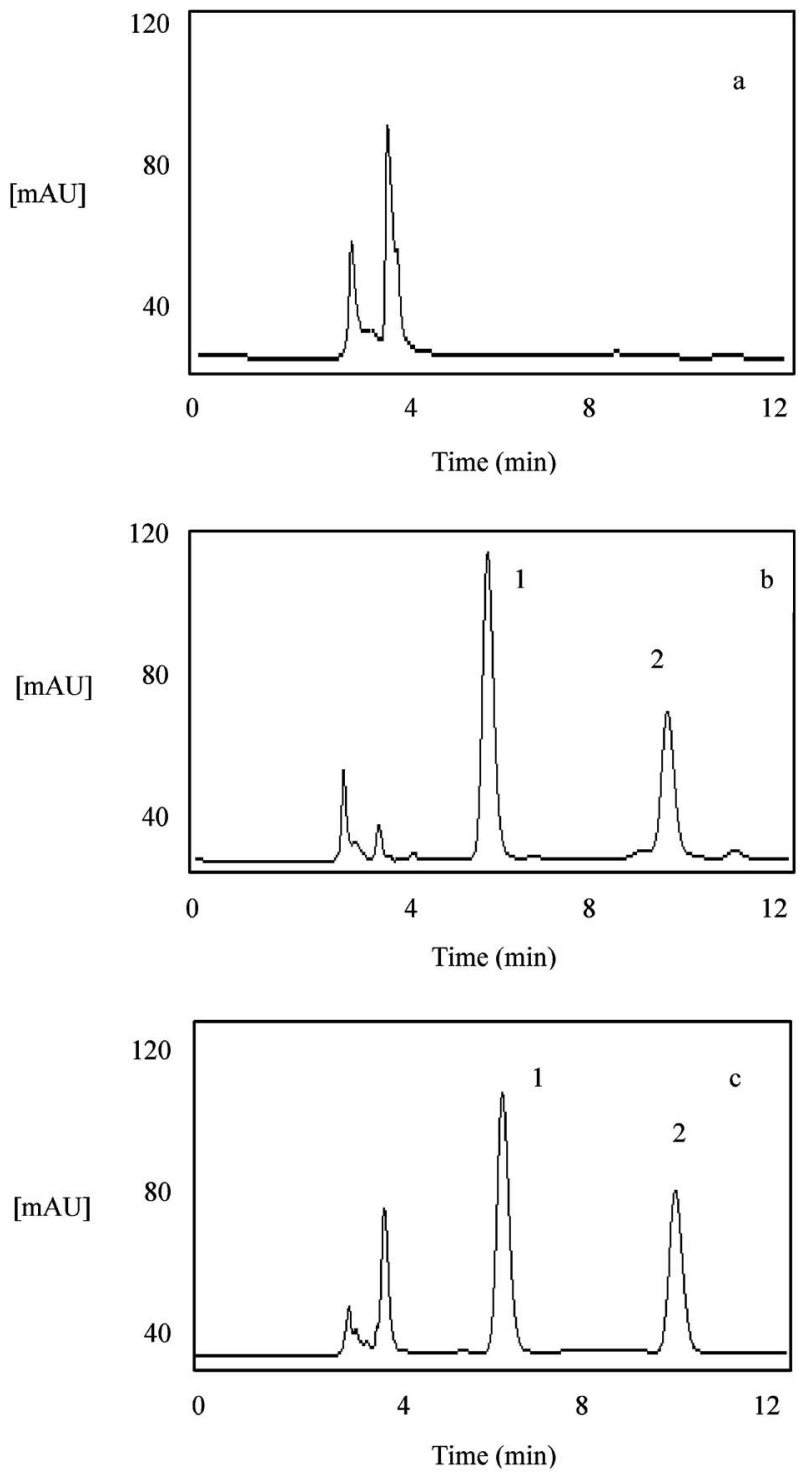

Fig. 2. RP-HPLC Chromatograms of Blank Plasma (a), Blank Plasma Spiked with Spinosin $(4.0 \mu \mathrm{g} / \mathrm{ml})$ and IS $(0.025 \mu \mathrm{g} / \mathrm{ml})$ (b), and Plasma Sample (45 min) after Intravenous Administration of Spinosin (c) . 1: spinosin, 2: IS.

lyzed. The linear regression of the curve for the peak area ratio $(Y)$ versus concentration $(C)$ was plotted for each type of sample. The $R^{2}$ values for the standard curves are also listed in Table 1 . The calibration curve of spinosin in plasma showed good linearity over the concentration range of $1-300 \mu \mathrm{g} / \mathrm{ml}$. The linear range of concentrations for spinosin in the heart, spleen, stomach, lung, testis, brain, and intestine was $0.1-40 \mu \mathrm{g} / \mathrm{ml}$, and that in the liver and kidney was $1-150 \mu \mathrm{g} / \mathrm{ml}$. All coefficients of correlation were between 0.9939 and 0.9980 .

Quality control samples $(1,40$, and $300 \mu \mathrm{g} / \mathrm{ml}$ for plasma; $0.1,4$, and $40 \mu \mathrm{g} / \mathrm{ml}$ for heart, spleen,
Table 1. Standard Curves, Correlation Coefficients and Linear Range of Spinosin in Biological Samples

\begin{tabular}{lccc}
\hline \hline \multicolumn{1}{c}{ Sample } & Standard curve & $R^{2}$ & $\begin{array}{c}\text { Linear range } \\
(\mu \mathrm{g} / \mathrm{ml})\end{array}$ \\
\hline Plasma & $\mathrm{Y}=0.00664+0.0693 \mathrm{C}$ & 0.9980 & $1-300$ \\
Brain & $\mathrm{Y}=0.00132+0.0824 \mathrm{C}$ & 0.9981 & $0.1-40$ \\
Heart & $\mathrm{Y}=0.0680+0.0992 \mathrm{C}$ & 0.9977 & $0.1-40$ \\
Liver & $\mathrm{Y}=0.1786+0.093 \mathrm{C}$ & 0.9940 & $1-150$ \\
Spleen & $\mathrm{Y}=0.0780+0.0389 \mathrm{C}$ & 0.9939 & $0.1-40$ \\
Lung & $\mathrm{Y}=0.00162+0.1803 \mathrm{C}$ & 0.9994 & $0.1-40$ \\
Kidney & $\mathrm{Y}=0.00355+0.0897 \mathrm{C}$ & 0.9947 & $1-150$ \\
Stomach & $\mathrm{Y}=0.1769+0.0917 \mathrm{C}$ & 0.9960 & $0.1-40$ \\
Intestine & $\mathrm{Y}=0.01582+0.2357 \mathrm{C}$ & 0.9985 & $0.1-40$ \\
Testis & $\mathrm{Y}=0.00156+0.1863 \mathrm{C}$ & 0.9980 & $0.1-40$ \\
\hline
\end{tabular}

stomach, lung, testis, brain, and intestine tissues; 1 , 25 , and $150 \mu \mathrm{g} / \mathrm{ml}$ for liver and kidney tissues) were processed to evaluate the accuracy and precision of the assay. Six replicate quality control samples of every tissue and plasma sample at each concentration were analyzed in a single sequence for within-day assessment. For between-day assessment, six replicate quality control samples of every tissue and plasma sample at each concentration were analyzed with standards on three occasions. The accuracy of the assay was determined by calculating the percentage of deviation of the observed concentrations from the nominal concentrations (relative error, RE\%). The accuracy was less than $8.6 \%$ for the analyte. The precision of the assay was determined by calculating the relative standard deviation. The intra- and interrun precision for all samples was less than $\leqslant 11.0 \%$ (data not shown). The recovery rates of spinosin from the spiked plasma or tissue samples were calculated using different quality control samples. Recovery was calculated by comparing the observed concentrations with the spiked concentrations. The mean recovery for all samples was greater than $96.8 \%$. The limit of quantitation was defined as the lowest drug concentration that can be determined with an RE and precision (relative standard deviation) of less than $20 \%$. The limit of quantitation in plasma was $1 \mu \mathrm{g} / \mathrm{ml}$. The limit of quantitation in the heart, spleen, stomach, lung, testis, brain, and intestine tissues was $0.1 \mu \mathrm{g} / \mathrm{ml}$. For liver and kidney tissues, the limit of quantitation was $1 \mu \mathrm{g} / \mathrm{ml}$. The limit of quantitation for all samples was sufficient for pharmacokinetic and tissue distribution studies.

The stability of spinosin in rat plasma and tissues 
was determined through three freeze-thaw cycles in corresponding quality control samples. The percentage of deviation from the concentration observed was less than $6.4 \%$. The results of the stability experiments indicated that spinosin is stable in rat plasma and tissues.

Pharmacokinetics in Plasma The concentration of spinosin in rat plasma was plotted against time (Table 2). Akaike's Information Criteria (AIC) values and pharmacokinetic parameters were calculated using 3P97 pharmacokinetic program software (Chinese Society of Mathematical Pharmacology). The AIC values of spinosin after intravenous administration were 11.3 and -3.1 for the one- and two-compartment models, respectively, when the weighting factor was selected as $1 / \mathrm{c}^{2}$ (the reciprocal of the square of the spinosin concentration). According to the minimum AIC, the time-concentration curve of spinosin after intravenous administration of a single dose of $20 \mathrm{mg} / \mathrm{kg}$ to rats corresponded to the two-compartment model. The pharmacokinetic parameters are listed in Table 3. The parameters showed that spinosin was distributed and cleared quickly in rats after intravenous administration.

Metabolites of spinosin in plasma or tissues were analyzed using the LC-MS-MS method after the collected samples were prepared with the solid-phase extraction method. Detectable methyl-, hydroxyl-, Noxide, or conjugated metabolites of spinosin such as

Table 2. Time-concentration Curve Data of Spinosin

\begin{tabular}{cccc}
\hline \hline $\begin{array}{c}\text { Time points } \\
(\mathrm{min})\end{array}$ & $\begin{array}{c}\text { Concentration } \\
(\mu \mathrm{g} / \mathrm{ml})\end{array}$ & $\begin{array}{c}\text { Time points } \\
(\mathrm{min})\end{array}$ & $\begin{array}{c}\text { Concentration } \\
(\mu \mathrm{g} / \mathrm{ml})\end{array}$ \\
\hline 0 & 0 & 30 & $37.6 \pm 4.8$ \\
2 & $252.7 \pm 6.1$ & 45 & $13.8 \pm 1.5$ \\
5 & $183.2 \pm 8.4$ & 60 & $7.67 \pm 0.34$ \\
10 & $122.9 \pm 1.0$ & 120 & $3.06 \pm 1.0$ \\
15 & $55.6 \pm 8.7$ & 240 & $1.21 \pm 0.11$ \\
\hline
\end{tabular}

sulphate, glucoside, and glucoronide metabolites were not found in collected samples.

Distribution in Tissues The biodistribution of spinosin in the brain, heart, liver, spleen, lung, kidney, stomach, intestine, smooth muscle, skeletal muscle, and testis of rats was determined using the assay method described above. The results are shown in Table 4. After intravenous administration, the drug was distributed extensively in rats in vivo and accumulated in the liver and kidney. The highest level of spinosin appeared in the liver, followed by the spleen and kidney. The lowest level of spinosin appeared in the testis. Drug levels in the liver, kidney, and spleen were markedly higher than those in the testis, lung, and brain. Spinosin was not detected in smooth and skeletal muscles. A low drug level was found in the brain, which indicated that spinosin passes through the blood-brain barrier. After $45 \mathrm{~min}$, spinosin was not detected in the brain under the present analytical conditions. The peak concentration of spinosin in

Table 4. Distribution of Spinosin in Tissues after Intravenous Administration to Rats $(n=5$, Mean \pm S.D. $)$

\begin{tabular}{lrrc}
\hline \hline \multirow{2}{*}{ Tissue } & \multicolumn{3}{c}{ Concentration $(\mu \mathrm{g} / \mathrm{g})$} \\
\cline { 2 - 4 } & \multicolumn{1}{c}{$5 \mathrm{~min}$} & \multicolumn{1}{c}{$20 \mathrm{~min}$} & $60 \mathrm{~min}$ \\
\hline Brain & $3.49 \pm 0.27$ & $5.93 \pm 0.10$ & nd \\
Heart & $42.85 \pm 0.81$ & $30.97 \pm 1.77$ & $7.32 \pm 0.74$ \\
Liver & $133.4 \pm 9.69$ & $220.3 \pm 4.37$ & $62.12 \pm 4.52$ \\
Spleen & $122.3 \pm 6.98$ & $29.86 \pm 5.22$ & $4.17 \pm 0.13$ \\
Lung & $5.60 \pm 0.29$ & $4.88 \pm 0.45$ & $1.68 \pm 0.14$ \\
Kidney & $174.1 \pm 6.35$ & $90.82 \pm 3.29$ & $51.03 \pm 6.30$ \\
Stomach & $26.96 \pm 0.84$ & $13.30 \pm 0.43$ & $6.30 \pm 0.85$ \\
Intestine & $15.27 \pm 0.67$ & $10.68 \pm 0.86$ & $7.76 \pm 2.59$ \\
Testis & $2.84 \pm 0.29$ & $2.64 \pm 0.28$ & $1.57 \pm 0.10$ \\
Smooth muscle & $\mathrm{nd}$ & $\mathrm{nd}$ & $\mathrm{nd}$ \\
Skeletal muscle & $\mathrm{nd}$ & $\mathrm{nd}$ & $\mathrm{nd}$ \\
Plasma $(\mu \mathrm{g} / \mathrm{ml})$ & $183.1 \pm 8.35$ & $37.64 \pm 4.85$ & $1.97 \pm 0.36$ \\
\hline nd: not detected. & & &
\end{tabular}

Table 3. Pharmacokinetic Parameters of Spinosin after Intravenous Administration to Rats $(n=5$, Mean \pm S.D.)

\begin{tabular}{lclc}
\hline \hline \multicolumn{2}{c}{ Parameters } & \multicolumn{2}{c}{ Parameters } \\
\hline$\alpha\left(\mathrm{min}^{-1}\right)$ & $0.104 \pm 0.0091$ & $K_{21}\left(\mathrm{~min}^{-1}\right)$ & $0.101 \pm 0.0033$ \\
$\beta\left(\mathrm{min}^{-1}\right)$ & $0.0139 \pm 0.0023$ & $K_{10}\left(\mathrm{~min}^{-1}\right)$ & $0.0982 \pm 0.0070$ \\
$T_{0.5 \alpha}(\mathrm{min})$ & $6.66 \pm 0.576$ & $K_{12}\left(\mathrm{~min}^{-1}\right)$ & $0.00841 \pm 0.0017$ \\
$T_{0.5 \beta}(\mathrm{min})$ & $51.5 \pm 11.7$ & $V c\left(\mathrm{~L} \cdot \mathrm{Kg}^{-1}\right)$ & $14.0 \pm 1.50$ \\
$\mathrm{AUC}_{0 \sim \mathrm{T}}\left(\mathrm{mg} \cdot \mathrm{min} \cdot \mathrm{ml}^{-1}\right)$ & $2.83 \pm 0.412$ & $C L s\left(\mathrm{~L} \cdot \mathrm{min}^{-1}\right)$ & $1.42 \pm 0.201$ \\
\hline
\end{tabular}


liver and brain tissues was found at 20 min and then began to decline with time, while the concentration of spinosin in other tissues continued to decrease with time.

The sedative and hypnotic effects of spinosin are closely related to its concentration in the brain $(3.49$ and $5.93 \mu \mathrm{g} / \mathrm{g}$ at $5 \mathrm{~min}$ and $20 \mathrm{~min}$, respectively). The pharmacokinetic study showed that spinosin accumulates quickly in the brain first and then begins to decrease. These results indicate that spinosin exhibits rapid pharmacologic effects after intravenous administration in spite of low drug levels. These findings were also supported by previous research, which showed that spinosin inhibits spontaneous motion and sleeping duration after intravenous administration to rats within $30 \mathrm{~min} .{ }^{5)}$

\section{CONCLUSION}

After intravenous administration of spinosin at a single dose of $20 \mathrm{mg} / \mathrm{kg}$ to rats, the time-concentration curve corresponded to the two-compartment model. Spinosin shows substantial penetration into most tissues and organs. The results of this study are helpful for the systematic assessment of the disposition of spinosin in vivo and understanding its pharmacokinetic behavior.

Acknowledgment We would like to thank the Base Research Found Commission of the Beijing Institute of Technology for financial support for this research.

\section{REFERENCES}

1) Sun K., J. Chin. Med. Sci., 44, 1168-1172 (1988).

2) State Pharmacopoeia Commission of the People's Republic of China, "Pharmacopoeia of the People's Republic of China, Vol. 2,", Chemical Industry Press, Beijing, 2005, pp. 254-255.

3) Woo W. S., Phytochemistry, 18, 353 (1978).

4) Shin K. H., Lee C. K., Woo W. S., Kang S. S., Arch. Pharm. Res., 7, 1 (1978).

5) Yuan C. L., Wang Z. B., Jiao Y., Chin. J. Chin. Mater. Med., 12, 34-36 (1987).

6) Kawashima K., Saito K., Yamada A., Obara S., Ozaki T., Biol. Pharm. Bull., 20, 11711174 (1987).

7) Li Y. J., "Study on the Therapeutic Material Basis of Traditional Chinese Medicinal Preparation Suanzaoren Decoction,' Doctoral thesis of Shenyang Pharmaceutical University, Shenyang, 2003.

8) Li Y. J., Bi K. S., Chem. Pharm. Bull., 56, 847-851 (2006).

9) Li Y. J., Li P., Li H. J., Bi K. S., Chin. Crude Herbs, 32, 1079-1080 (2001).

10) Li Y. J., Li P., Li H. J., Bi K. S., J. Chin. Pharm. Aana., 22, 208-210 (2002).

11) Li Y. J., Bi K. S., Chin. Crude Herbs, 35, 754756 (2004).

12) Li Y. J., Liang X. M., Xiao H. B., Bi K. S., J. Chromatogr. B, 787, 421-425 (2003).

13) Li Y. J., Bi K. S., Acta Pharm. Sin., 38, 448450 (2003). 